\title{
ORIGEN DE LA MATERIA TRISTANIANA: ESTADO DE LA CUESTION
}

\author{
M. ${ }^{a}$ Luzdivina Cuesta Torre \\ Universidad de León
}

El tema de Tristán es fundamental en la literatura europea medieval. Para conocerlo en profundidad es necesario estudiar su origen y sus fuentes. Los textos más antiguos conservados sirven de punto de partida en esta búsqueda. Estos señalan hacia la existencia de un arquetipo cuya naturaleza permanece oscura. A través de su análisis se percibe la influencia de tradiciones culturales muy diversas que prestan al tema un matiz universal.

Palabras clave: arquetipo, orígenes célticos/orientales, fuentes, leyendas, Tristán.

The theme of Tristan is one of the most important material of the Medieval European Literature. In order to Know it well it is necessary to study its origins and sources. The more ancient texts talk about legends and other story-tellers. This shows that there were some previous versions of this argument had been searched in the celtic tradition, in the clasics, in the oriental culture...

Words: archetype, origins celtic/oriental, legend, sources, Tristan.

El tema de Tristán es uno de los mitos básicos de la cultura europea. Su fama y difusión fue enorme en la época medieval y llegó a convertirse en el mito sobre el amor por excelencia. Los nombres de Tristán e Iseo pasaron entonces a engrosar la lista de los amantes clásicos en un puesto de honor, compitiendo ventajosamente con los de Paris y Helena, Eneas y Dido o Píramo y Tisbe. Emmanuèle Baumgartner resalta la importancia del tema cuando dice:

"Le Tristán es d'abord un récit légendaire dont la genèse nous est bien mal connue et qui a donné naissance dès le XII ${ }^{e}$ siècle à l'un des mythes fondateurs de l'Occident, le mythe de l'amour fatal menant à la mort, Eros et Thanatos indissolublement mêlés"l.

Desde la primera versión escrita que conocemos hasta la versión wagneriana, la leyenda de Tristán e Isolda no ha dejado de conocer en toda Europa sucesivas traducciones y adaptaciones. La materia tristaniana se constituye en un conjunto de textos muy diversos que van desde los primeros romans en verso en francés, en el siglo XII, pasando por las adaptaciones al alemán de Eilhart von Oberg y de Gottfried von Strassburg, la noruega de Robert, de 1226, hasta el enorme roman en prosa francés del siglo XIII (a la manera de las versiones cíclicas de la materia artúrica, con la que entronca), y, a partir de él, muchas otras versiones europeas, como la vasta compilación italiana del Tristano Riccardiano o la conocidísima Morte Darthur de Thomas Malory, ya a finales

1. BAUMGARTNER, Emmanuèle, Tristân et lseut. De la légende aux récits en vers, Paris, Presses Universitaires de France, 1987, p. 5. 
de la Edad Media. Tras la invención de la imprenta la leyenda continuó su difusión y se sucedieron las ediciones tanto en Francia como en el resto de Europa ${ }^{2}$.

El argumento es de sobra conocido. Los hechos principales son los siguientes:

Rivalín, rey de Leonís, se casa con Blancaflor, hermana del rey Mares de Cornualles. Ella muere al alumbrar un niño: Tristán. Rivalín lo confía a los cuidados de Governal. Tristán, aconsejado por éste, va de incógnito a la corte de su tío, donde gana la estima de todos por su gentileza y su habilidad con el arco y con el arpa. El rey de Irlanda envía a su cuñado, el Morlot, a recaudar un tributo a Cornualles. Este desafía a los caballeros de Cornualles diciendo que, si es vencido, quedarán libres del tributo. Pero ninguno acepta el duelo. Tristán pide que le armen caballero y revela su identidad. Combate con el Morlot y lo vence, pero queda herido y sufre tanto que se embarca, esperando que el azar lo lleve ante alguien capaz de curarle. La barca a la deriva llega a las costas de Irlanda donde, escondiendo su identidad para que no lo reconozcan como el homicida del Morlot, obtiene del rey la gracia de quedar al cuidado de la princesa Iseo. Ella consigue curarle y Tristán regresa a Cornualles. Allí, la gran estima que le tiene el rey Mares despierta la enemistad de los cortesanos, que incitan al rey a casarse para que Tristán no herede el reino. El rey accede con tal de que su esposa sea la dueña de un cabello dorado que le han traído unas golondrinas, creyendo imposible encontrar a esa mujer. Tristán se ofrece a ir en su busca. El azar le lleva otra vez a Irlanda donde consigue matar a un dragón, obteniendo así la mano de la princesa, pero queda inconsciente. Un senescal encuentra el dragón muerto y pretende haber sido él quién mató al monstruo. Iseo sospecha que es mentira y va al lugar de la batalla, donde yace Tristán con la lengua del dragón escondida. Ella le prepara un baño reparador del veneno de la fiera y descubre, por una melladura de su espada, que se trata del asesino de su tío. Por consejo de su doncella Brangel obtiene el perdón para Tristán, pues de otro modo no podría probar el engaño del senescal y debería casarse con él. Durante el viaje por mar de regreso a Cornualles, Tristán e Iseo beben por error el brebaje amoroso que la madre de Iseo había preparado para la noche de sus bodas con Mares. Quienes beban del filtro se amarán apasionadamente durante 4 años, de modo que si están separados más de una semana, morirán. La pasión amorosa se apodera de ellos y desde entonces serán amantes. A pesar de su amor recíproco, Tristán entrega a Iseo al rey, que se casa con ella. Brangel substituye a la novia en la noche de bodas y el rey no nota la falta de su mujer. Tiempo después Iseo teme que su doncella traicione su secreto y ordena matarla. Brangel consigue conmover a los asesinos, que no cumplen la orden de la reina. Esta se arrepiente y, cuando descubre que su doncella está viva, la recibe con alegría. Brangel la perdona. Iseo engaña al rey con Tristán y su amor adúltero acaba por ser descubierto por los cortesanos envidiosos, que los delatan, y Mares expulsa a Tristán de la corte. Los envidiosos descubren el lugar donde se han citado los amantes gracias a un enano adivino y se lo dicen al rey, que los espía; pero ellos se dan cuenta y salvan la si-

2. Este tema no dejó de tener resonancia en la Península Ibérica, donde la leyenda ofrece varias refundiciones: el Cuento de Tristán de Leonís y otros fragmentos manuscritos de diferente longitud fechados en su mayoría en los siglos XIV y XV, el Libro del buen cavallero... don Tristán de Leonís, que tuvo varias ediciones a lo largo del siglo XVI y que parece basarse en un manuscrito del XIV, y, por último, la Corónica nuevamente emendada y añadida del libro del buen cavallero... don Tristán de Leonis, editada en Sevilla en 1534. Véase la bibliografía de SHARRER, Harvey L., A critical bibliograhy of Hispanic Arthurian material, London, Grant and Cutler, 1977, pp. 25-32. La materia tristaniana peninsular constituye todavía un campo de estudio casi inexplorado. Sin embargo, no es éste el tema que nos ocupa, sino el problema del origen de esta leyenda que marca las características del ideal amoroso de nuestra cultura. 
tuación. Tristán obtiene el perdón. Los cortesanos derraman harina entre los lechos de los enamorados, Tristán salta sobre ella sin dejar huella, pero el salto abre una herida y mancha de sangre la cama de la reina. Mares los condena a muerte, aunque después cambia la pena de Iseo por la de ser entregada a los leprosos. Tristán escapa mediante un salto prodigioso y libera a Iseo. Los amantes consiguen huir al bosque, donde se refugian por algún tiempo. Un día el rey los encuentra dormidos, pero Tristán ha colocado su espada entre los dos: el rey ve en esto la prueba de su inocencia y se marcha, dejando como señal de su visita su guante, su anillo y su espada, y llevándose la de Tristán. Al cabo de un tiempo desaparece el efecto del filtro y los amantes se dan cuenta de su penosa situación. El ermitaño Ogrín consigue reconciliarlos con el rey, que admite de nuevo a su mujer, pero destierra a Tristán. Al principio Tristán permanece escondido cerca de la corte para comprobar que Iseo no corre peligro, pero después va a la corte del rey Arturo. En una ocasión Arturo y sus caballeros van a cazar al castillo de Mares, y Tristán duerme con Iseo, pero se hiere con unas hoces que Mares había hecho colocar alrededor del lecho. Todos los caballeros de Arturo se hieren también, para encubrirle. Tristán ayuda en una guerra al rey Hoel de Bretaña y se hace amigo del hijo de éste, Quedín. Un día suspira por Iseo. Quedín piensa que se trata de su hermana Iseo "de las blancas manos" y se la ofrece en matrimonio. Tristán acepta, pero en la noche de bodas el recuerdo de Iseo "la rubia" le impide consumar el matrimonio. Pasado algún tiempo Quedín descubre esto, mediante el episodio del agua atrevida ${ }^{3}, y$, ofendido, solicita una explicación a Tristán. El le cuenta la verdad y ambos deciden ir a Cornualles para ver a la reina Iseo. A este viaje inicial suceden otros: Tristán regresa a Cornualles disfrazado de leproso, de peregrino, de juglar y de loco. El relato finaliza cuando Tristán recibe una herida que sólo Iseo "la rubia" puede curar. Envía a buscarla y pide que, si regresan con ella, usen velas blancas. Si ella no viene las traerán negras. Iseo "de las blancas manos" oye esta conversación y cuando ve regresar el barco con velas blancas, cegada por los celos, le dice a Tristán que las velas son negras. Cuando llega la reina Iseo, abraza su cadáver y muere sobre él. Por fin, al conocer la magia del filtro amoroso, el rey Mares los perdona y los hace enterrar juntos. Sobre sus tumbas crecen un rosal y una viña que entrelazan sus ramas.

Este es, en líneas generales, el argumento que desarrolla el Tristrant de Eilhart von Oberg $^{4}$, único poema del siglo XII (el manuscrito es de 1180 aproximadamente, y la composición parece ser una decena de años anterior, de hacia 1170) que conservamos completo.

Tradicionalmente, siguiendo a J. Bédier y a G. Schoepperle, se venía dividiendo los textos en dos grupos: el constituido por la versión común y el formado por los textos que siguen la llamada "versión cortés". A la versión común pertenece la obra de

3. Una gota de agua de una fuente salpica a Iseo de las blancas manos en los muslos y ella se manifiesta asombrada del atrevimiento del agua, que llega más lejos de lo que nunca llegó la mano de ningún hombre.

4. Para la traducción de los nombres utilizo los empleados en las versiones medievales castellanas. El poema de Eilhart es considerado el testimonio más fiel de la leyenda primitiva por parte de G. Schoepperle y de Delbouille. Sin embargo, Buschinger ha llegado a la conclusión de que Eilhart efectuó varios retoques, inscribiendo su narración en una arquitectura bien estructurada y suprimiendo unos episodios y añadiendo otros. (RAYNAUD DE LAGE, Guy, "Les romans de Tristan au XIIe siècle", Grundiss der Romanischen Literaturen des Mittelalters. Volume IV/l: Le roman jusque'à la fin du XIIIe siècle, Heidelberg, Carl Winter-Universitätsverlag, 1978, pp. 211230).

5. J.C. Payen considera inadecuada esta nomenclatura y se muestra partidario de denominar estas corrientes "versión épica" y "versión lírica" respectivamente, añadiendo una tercera tradición, 
Béroul $^{6}$ y los poemas derivados de ella: el Tristrant de Eilhart ${ }^{7}$ y el poema episódico de la Folie Tristan, conservado en el manuscrito de Berna (c. 1170), además del Tristan en prosa francesa. La versión cortés está constituida a su vez por el poema de Thomas ${ }^{8}$ y los textos derivados de él: el fragmento de la Folie de Oxford, la obra inacabada de Gottfried von Strassburg (1200-1210) y la adaptación noruega de Robert. Otros textos sobre Tristán, que no se adhieren a ninguno de estos grupos, son el lai de Chèvrefoil de María de Francia, el poema anglo-normando titulado Donnei des Amanz de fines del XII y la continuación de Perceval de Gebert de Montreuil, compuesta hacia 1230.

Además de los textos conservados, tenemos testimonios de la existencia de otras versiones que no han llegado a nosotros. Así ocurre con la obra de Chrétien de Troyes, Del roi Marc et d'Ysalt la blonde, mencionada por el propio autor en su Cligès ${ }^{\text {' }}$. Respecto al Tristan del poeta La Chièvre, sabemos de su existencia a través del Roman de Renard ${ }^{10}$.

A la hora de plantearse los orígenes del tema de Tristán habrá que acudir, por tanto, a los poemas de Béroul ${ }^{11}$ y Thomas $^{12}$, de los que derivan los demás, pero sin dejar

la de la "versión caballeresca", a la que adjudica el Tristán en prosa. La versión épica se caracteriza por su objetividad y su carácter trágico, la abundancia de exhortaciones al público, la ausencia casi total de análisis psicológicos y la trama discontinua. La versión lírica multiplica los monólogos afectivos y la retórica trovadoresca. (PAYEN, Jean Charles (ed.), Les Tristan en vers. Tristan de Béroul, Tristan de Thomas, Folie Tristan de Berne, Folie Tristan d'Oxford, Chèvrefoil de Marie de France, Paris, Bordas, 1989, pp. VII-VIII, correspondientes a la "Introducción").

6. La obra de Béroul presenta muchas dificultades para su datación. En cualquier caso, el estudio de la lengua indica que el texto se compuso a finales del siglo XII. Existe una teoría, ahora prácticamente desechada, según la cual el poema debía ser posterior al asedio de San Juan de Acre, basándose en que se cita el "mal de Acre" en el verso 3349. Sin embargo, G. Whitteridge ("The date of the Tristan of Béroul", en Medievum Aevum, XXVIII, 1959, pp. 167-171) advierte que la enfermedad que sufrieron los cruzados durante dicho asedio tenía unas características muy diferentes a las que se describen en el poema. Por otra parte, la grafía del texto no está muy clara.

7. Para J. Bédier, G. Schoepperle y sus seguidores, el poema de Eilhart no procede del de Béroul, y sus semejanzas se explican por tener una fuente común.

8. El texto de Thomas nos ha llegado muy deteriorado: se conservan cinco manuscritos entre los que se reparten ocho fragmentos de longitud desigual y 3146 versos, con multitud de alteraciones debidas a los copistas. El argumento de las porciones perdidas puede ser reconstruido a través del texto de Gottfried von Strassburg y la Saga noruega.

9. Ed. A. Micha, Paris, Champion, 1968, v. 5, p.1.

10. "Seigneurs, oï avez maint conte / Que maint conterre vous raconte: / Conment Paris ravi Elaine, / Le mal qu'il en ot et la paine, / De Tristan qui la Chievre fist, / Qui assez bellement en dist / et fabliaus et chançon de geste". (Romand de Renard. II Branche, ed. Luis Cortés Vázquez, Salamanca, Ediciones de la Universidad de Salamanca, 1979, rr. 1-7).

11. Se conserva en un único manuscrito de la segunda mitad del siglo XIII que no tiene ni principio ni final: comienza y termina en el medio de una frase. Además hay otras lagunas a lo largo del texto. El fragmento consta de 4485 versos. Comienza en la escena del encuentro de los amantes debajo de un árbol desde el cual les espía el rey. El final abrupto corta la escena en la que Tristán mata con una flecha a uno de los traidores que se esconde, también, en un árbol.

12. La historia de Thomas no admite la comparación con la de Béroul, pues los episodios conservados de cada poema no coinciden. El fragmento conservado de la obra de Béroul termina antes de la partida de Tristán a la Pequeña Bretaña, en cambio, los fragmentos que poseemos del poema de Thomas corresponden a la parte final de la narración: una breve escena de Tristán e Iseo en el jardín, el matrimonio de Tristán con Iseo de las blancas manos, el intento de Cariadoc de con- 
de tener en cuenta que existen otros poemas breves ${ }^{13}$, que narran episodios aislados no contemplados en ninguna de estas dos primeras versiones ${ }^{14}$.

Respecto a los orígenes del tema se plantea un primer problema: la naturaleza del arquetipo que sirvió de base a las obras que han llegado a nosotros. Pueden darse básicamente dos casos:

- El argumento es obra de un autor concreto, que inventa su propia historia tomando elementos de la sociedad en que vive y de su acervo cultural personal. En este caso, el problema de los orígenes del tema tristaniano se limitaría a intentar encontrar el texto y el autor primigenios, y posteriormente, a discutir sus fuentes. Actualmente esta hipótesis ha sido prácticamente desechada.

- La materia relativa a Tristán existe como un cuerpo de leyendas, cuentos o pequeños poemas populares, y es posteriormente recreada artísticamente, dado su carácter fragmentario y tradicional, por varios autores que recogen esa tradición de manera distinta. Entonces los orígenes del tema habría que buscarlos en la materia tradicional de la cultura que le dio vida, aunque también sería posible bucear en las fuentes que cada autor hubiese utilizado en la elaboración de su versión personal. Esta teoría no descarta la posibilidad de que varias de las versiones que poseemos tengan un antepasado común, pero éste no sería el arquetipo, sino una versión intermedia.

La teoría de la existencia de una arquetipo tristaniano fue lanzada a principios de siglo por W. Golther y Bédier: después de haber analizado las concordancias de los distintos textos llegaron a la conclusión de que todos ellos procedían de una fuente común. Bédier caracterizó este arquetipo o primera narración sobre Tristán como un poema regular, del principio del siglo XII, escrito por un hombre de genio ${ }^{15}$. Más adelante, G. Schoepperle ${ }^{16}$, hizo una puntualización a esta teoría: para ella solamente proceden directamente del arquetipo las narraciones de Béroul, Eilhart, Thomas y la Folie de Berna, siendo la de Eilhart la que le sigue de modo más fiel. La fecha en que debería situarse éste difiere de unos autores a otros, aunque siempre en el siglo $\mathrm{XII}^{17}$.

Estos autores hablan del arquetipo como de una historia perfectamente construida que recogiese todos los episodios de la materia tristaniana de una manera unívoca. Sin

quistar el amor de Iseo, la creación de la "sala de las imágenes", el episodio del agua atrevida, el del primer viaje de Tristán y Quedín a Cornualles, y el largo fragmento que recoge el final del poema.

13. Como, por ejemplo, el lai de Chèvrefoil o los episodios de las Folie, o el del Donnoi des amants.

14. El poema de Béroul (c. 1230) y el poema episódico de la Folie Tristan, conservado en el manuscrito de Berna (c. 1170): J. Bédier considera que éstas son las cinco versiones primarias que hoy poseemos de la leyenda. Véase BEDIER, Joseph, Le Roman de Tristan par Thomas: poème du XIle siècle, Paris, SATF, 1902, 1905, reimp. Oxford, Pollard, 1961.

15. BEDIER, J., Le roman de Tristan par Thomas, Tome II: Introduction, Paris, STAF, 19025, p.186.

16. SCHOEPPERLE, G., Tristan and Isolt, A study of the sources of the Romance, New York University, 1970 (2. edición revisada).

17. "L'arquétype a été très différemment daté: Bédier le situait avant 1154, Golther entre 1140 el 1150, G. Schoepperle estimait que l'estoire n'avait pas été composée avant les dernières décades du XII siècle tandis que J. Frappier, nuançant à son tour la théorie de l'archétype, le plaçait au milieu du XIIe siècle. Selon J. Carney enfin, il aurait existé dès l'an 800 un Tristan primitif, d'origine britannique, prototype de tous les récits ultérieurs". (BAUMGARTNER, op. cit., p.15). 
embargo, otros autores, como E. Baumgartner ${ }^{18}$, señalan la posibilidad de que éste consistiese en un conjunto de cuentos, leyendas populares y escritos que tuviesen por personajes centrales a Tristán y a Iseo. A favor de esta idea están las palabras de los propios Béroul y Thomas, que se erigen en defensores de una determinada manera de contar la historia. Ambos señalan que la suya es la "verdadera" historia de Tristán e Iseo, y que, los que lo cuentan de otra manera, no conocen bien el argumento. Incluso hacen referencia a fuentes escritas. Thomas, en los versos $852-884$ se expresa así:

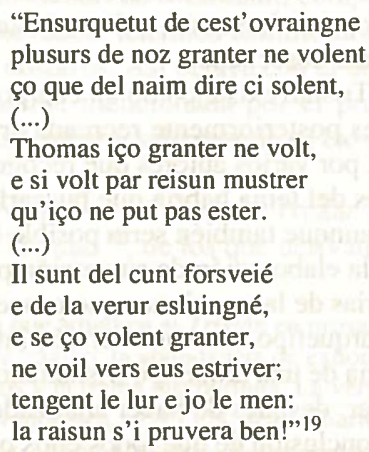

También el mismo Thomas, en los versos 835-51 del manuscrito de Douce, señala la existencia de diversidad en el modo de contar la historia:

"Seignurs, cest cunte est mult divers,
e pur ço l'uni par mes vers
e di en tant cum est mester
e le surplus voil relesser.
Ne vol pas trop en uni dire:
ici diverse la matyre.
Entre ceus qui solent cunter
e del cunte Tristan parler,
il en cuntent diversement:
oï en ai de plusur gent.
Asez sai que chescun en dit
e ço que il unt mis en escrit,
mes sulun ço que j’ai oï
nel dient pas sulun Breri
ky solt les gestes e les cuntes
ki orent esté en Bretaigne"20.

18. op. cit., pp. 14-15.

19. Victoria Cirlot ofrece una traducción de estos versos en su edición castellana del poema de Béroul (BEROUL, Tristán e Iseo, Barcelona, PPU, 1986, p. 19-20).: "En lo que respecta a esta obra, muchos de nosotros no estamos de acuerdo con lo que suelen contar del enano (...) Thomas no está de acuerdo y quiere demostrar que no pudo ser así. (...) Se han apartado del cuento y alejado de la verdad. Si no lo quieren aceptar, no pienso discutir con ellos. ¡Que sigan con su cuento y yo con el mío! ¡Ya se demostrará quién tiene razón!"

20. (BEROUL, Tristán e Iseo, Barcelona, PPU, 1986, p.18).: "Señoras, este cuento es muy di- 
Béroul, por su parte, habla en este sentido en los versos 1265-1270:
"Li conteor dient qu'Yvain
firent nïer, qui sont vilain;
n'en sevent mie bien l'estoire,
Berox l'a mex en sen memoire,
trop ert Tristan preuz et cortois
a ocirre gent de tes lois"2l.

Y más adelante hace referencia a una fuente escrita en los versos 1789-1790:

"Ne si conme l'estoire dit, la ou Berox le vit escrit"22.

Todo parece indicar que en el tiempo en que escriben Béroul y Thomas existían varias leyendas relativas a Tristán, e incluso obras escritas, que diferían sensiblemente en algunos detalles, aunque no en la marcha general de la narración. Y en este mismo sentido se expresa María de Francia en su lai Chèvrefoil (vv.5-10):
"Plusurs le m'unt cunté e dit
e jeo l'ai trové en l'escrit
de Tritram e de la reïne,
de lur amur que tant fu fine,
dunt il eurent meinte dolur,
puis en mururent en un jur"23.

Así pues, se puede llegar con cierta seguridad a la conclusión de que en el tiempo en que escriben estos tres autores existían varias versiones de la leyenda tristaniana y que éstas eran tanto orales como escritas. No se puede descartar la existencia de una obra escrita antepasada de las que conocemos o de algunas de ellas, pero es más razonable pensar que las diferencias a que se refieren Béroul y Thomas se hallan más bien

verso: por eso lo he unido con mis versos, relato lo necesario y me dejo el resto. Pero no quiero unificarlo demasiado, cuando tan diversa es la materia. Diversamente lo cuentan los que suelen hablar del conde Tristán; lo he oído a muchas gentes. Sé muy bien lo que dice cada uno y lo que han escrito, pero según lo que he oído no lo cuentan como Breri que sabe las gestas y cuentos de todos los reyes y todos los condes que han estado en Bretaña".

21. (BEROUL, Tristán e Iseo, Barcelona, PPU, 1986, p.20).: "Los cuentistas, que son villanos, dicen que ahogaron a Yvain: no saben bien la historia. Béroul la guarda en su memoria. Tristán era demasiado noble y cortés para matar a gente de aquel tipo".

22. (BEROUL, Tristán e Iseo, Barcelona, PPU, 1986, p.21):: "Tal y como cuenta la historia donde Béroul la vio escrita".

23. Les Tristan en vers. Tristan de Béroul, Tristan de Thomas, Folie Tristan de Berne, Folie Tristan d'Oxford, Chèvrefoil de Marie de France (edición de Jean Charles Payen), Paris, Bordas, 1989, p.229. Una posible traducción es la de Luis Alberto de Cuenca (MARIA DE FRANCIA, Los lais, Madrid, Siruela, 1987, p.89).: "Varias personas me han contado (incluso lo he encontrado por escrito) la historia de Tristán y de la reina, del amor tan tierno que se profesaron y por el que tanto sufrieron hasta morir, al fin, un mismo día". 
en la boca de los cuentistas ${ }^{24}$. El mismo hecho de que conozcamos la existencia de otras versiones de Tristán que no han llegado a nosostros atestigua que se trataba de una historia muy popular, cuyo origen no está en una obra concreta de un determinado autor. En el caso de que la historia hubiese sido inventada por un autor concreto, es de suponer que los narradores posteriores harían alguna referencia a él y no se atreverían a modificar la historia en cuanto a contenido, aunque la aplicasen las técnicas medievales de amplificatio, reductio, etc.

En cualquier caso, ya procedan las obras que poseemos de un poema anterior, ya sean, como parece más probable, la creación de unos autores que tomaron como base leyendas populares, la materia tristaniana está formada de un conjunto de elementos cuya procedencia no es posible ignorar sin restarle comprensión.

El origen de la materia relativa a Tristán ha sido muy discutido por parte de los estudiosos. Tal vez sea útil hacer aquí una distinción entre orígenes y fuentes. Hablar de orígenes supone aceptar que la leyenda nace en una determinada cultura. Hablar de fuentes hace referencia a la existencia de un autor individual que utiliza en su creación su propio acervo cultural. Se han planteado hipótesis que relacionan algunos elementos de la materia tristaniana con la literatura clásica griega y latina. Muchos de los episodios del Tristán enlazan, por sus obvias semejanzas, con motivos folklóricos. Sin embargo, aunque hay quienes defienden que la literatura clásica o el folklore intervienen en el origen de la historia de Tristán, parece más lógico suponer que se trata de fuentes utilizadas por los autores para enriquecer sus versiones o de elementos que se han superpuesto sobre el argumento original. Dos teorías presentan hoy argumentos convincentes sobre el origen de la materia relativa a Tristán: la teoría del origen céltico y la del origen oriental.

La teoría del origen celta es mayoritariamente aceptada hoy día: Gaston Paris, Zimmer, Bédier, Deutschbein, Ranke, Kelemina, Thurneysen, Schoepperle ${ }^{25}$, Loomis, Bromwich, Jean Marx, Panvini, entre otros, han defendido este punto de vista. Estos críticos suponen que șe trata de una leyenda nacida en país picto, es decir, en la Escocia arcaica, de donde emigró, en diversas etapas, hacia Irlanda, el país de Gales y Cornualles. Los bretones de Gran Bretaña pasaron en los siglos V y VI a la península armoricana, a la que dieron su nombre. Estos hombres conservaron celosamente su lengua, sus viejas tradiciones literarias y sus cuentos antiguos, que constituían su identidad cultural. En Armórica encontramos una población poco numerosa y de cultura parecida a la suya. En este ambiente desarrollaron las leyendas relativas a sus héroes. Entre estos personajes legendarios figuraba, para Jean Marx ${ }^{26}$ y otros partidarios del origen celta de la materia de Bretaña, el rey Arturo, Merlín, los caballeros de la Tabla Redonda y Tristán.

24. En este sentido, junto a otros muchos, se expresa Philippe Walter: “A l'origine, il n'existe donc pas de roman au sens moderne du mot mais plutôt des contes ou des lais plus ou moins autonomes sur Tristan et Yseut. (...) Une telle conception de la création littéraire rend délicate aujourd'hui l'étude de ces oeuvres en perpétuelle métamorphose, car il est facile de confondre les versions différentes d'un même récit et malaisé de concilier les épisodes contradictoires d'une même histoire". (Le gant de verre. Le mythe de Tristan et Yseut, Editions Artus, 1990, p.10).

25. El estudio más completo sobre la influencia celta es el de SCHOEPPERLE, Gertrude, Tristan and Isolt: A Study of the Sources of the Romance, Francfort-sur-le-Main and Londres, 1913; reimp. New York, Burt Franklin, 1959.

26. MARX, Jean, Les littératures celtiques, París, P.U.F., 1967, p. 119-120. 
A la sombra de la naciente materia artúrica el tema tristaniano fue cobrando vigor y llamó la atención de escritores de lengua francesa. Como señala Marcelino Menéndez Pelayo $^{27}$, con las invasiones sajonas la población celta de Gran Bretaña quedó reducida al país de Gales y a Cornwal. Cuando los normandos conquistan Inglaterra son bien recibidos por los bretones, con quienes hacen causa común contra los sajones. Esto hizo que se estableciera cierta afinidad cultural entre los dos pueblos ${ }^{28}$. Victoria Cirlot considera probable "que los escritores del norte de Francia se hubieran acercado al mundo céltico a través de la oralidad"29. De la confluencia de las culturas bretona y normanda surgieron las primeras versiones escritas de la leyenda de Tristán. De ahí que los elementos célticos estén mezclados con otros de distintas procedencias.

Numerosos argumentos favorecen la aceptación de la teoría del origen celta de la materia tristaniana. La primera manifestación de esta influencia se da en el marco espacial de la narración. Parece lógico suponer que los escenarios en los que ésta se desarrolla vengan determinados por el lugar donde se originó la leyenda. Los espacios geográficos en los que la historia tiene lugar son Irlanda (la patria de Iseo), Cornualles (reino de Mares), Bretaña (donde Tristán se casa con Iseo de las blancas manos) y el propio reino del héroe, Leonís, en Escocia. Es decir, la geografía del Tristán se identifica con una zona que, incluso en los siglos XI, XII y XIII, mantenía todavía viva la cultura celta.

El nombre del héroe se relaciona también con dicho origen. Los nombres de Drust y Talorc, principes pictos históricos (padre e hijo) que reinaron en el norte de Escocia a finales del siglo VIII, se encuentran posteriormente en las triadas galesas como Drystan o Trystan, hijo de Tallwch. Alicia Yllera señala que:

“... en las triadas galesas, conservadas en manuscritos del siglo XIII o posteriores, existen diversas menciones de Drystan: es citado entre los tres sometedores de enemigos de la isla de Bretaña (triada n. 19) es uno de los tres porqueros poderosos (n. 26), uno de los tres enamorados que poseen caballos célebres (n. 41). La triada de Los tres porqueros principales relata una breve intriga entre Drystan y Essyllt" 30 .

Helaine Newstead recuerda que, aunque los pictos desaparecieron como pueblo separado despues del año 843 , sin que nos quede nada de su lenguaje excepto algunas inscripciones, se ha preservado un precioso fragmento de la leyenda que se tejió alrededor del nombre de Drust en la saga irlandesa del siglo X El cortejo de Emer ${ }^{31}$. Su argumento es el siguiente:

El héroe llega con sus compañeros a una isla, oyen lamentos y se enteran de que la hija del rey va a ser entregada como tributo a tres piratas. El héroe combate con ellos y la li-

27. MENENDEZ PELAYO, Marcelino, Orígenes de la novela, Santander, Aldus, 1943, tomo I, pp. 252-253.

28. Op. cit., pp. 253.

29. La novela artúrica. Orígenes de la ficción en la cultura europea, Barcelona, Montesinos, 1987, p. 37.

30. YLLERA, Alicia, "Introducción" a su edición de Tristán e Iseo, Madrid, Alianza Editorial, 1984, pp. 20.

31. NEWSTEAD, H., "The origin and growth of the Tristan legend", LOOMIS, R. S. (ed.), Arthurian Literature in the Middle Ages, Oxford, Clarendon Press, 1959, pp. 126. 
bera sin desvelar su identidad. En la batalla recibe una herida. Más tarde otros invitados blasonan de ser ellos los vencedores de los piratas, pero la princesa no les cree. Prepara un baño y hace venir a los huéspedes uno a uno. Cuando entra el héroe, lo identifica por su herida ${ }^{32}$.

Dos de los temas típicos de la literatura irlandesa aparecen en Tristán: El motivo del immrama (viaje a la deriva hacia el mundo del más allá y que equivale a la navegación de Tristán, herido, a Irlanda) y el del aithed (rapto, paralelo al segundo viaje de Tristán a Irlanda con intención de llevarse a Iseo).

Por otra parte, según G. Schoepperle y otros eruditos, las líneas fundamentales de la leyenda de Tristán presentan gran semejanza con las de un cuento irlandés del género de los aitheda (cuentos de raptos), titulado Diarmaid y Grainne. G. Raynaud de Lage resume así el argumento:

Grainne, esposa de Finn, trata de seducir al sobrino de Finn, Diarmaid. Grainne logra su amor a través de un geis y le obliga a que la rapte. Diarmaid y Grainne huyen a un bosque perseguidos por Finn. Cada noche Diarmaid coloca una piedra entre su cuerpo y el de Grainne y cada mañana deja un trozo de carne cruda como medio de expresión de que no ha tocado a la mujer de su tío. Al final Diarmaid cede a la pasión de Grainne. Un protector del otro mundo, Oengus, salva a Grainne y obtiene para los amantes el perdón de Finn $^{33}$.

M. Jean Marx ha señalado que el origen del filtro podría estar en el sortilegio de geis, que la dama impone al amante de su elección y que éste no puede dejar de obedecer.

Guy Raynaud de Lage $^{34}$ señala, además, otro elemento que demuestra la filiación de esta leyenda con dicha cultura: El cuento de las orejas del rey Mares, es un cuento anomástico típico de la cultura celta, ya que Marc ${ }^{35}$ significa "caballo" en céltico.

Cuando la leyenda emigra a Bretaña las relaciones entre los principales personajes están ya establecidas, pero recibe nuevas influencias: el nombre del padre de Tristán cambia y pasa a ser Rivalen porque un señor de Vitré que vivió hacia 1030-1045 y cuyo padre se llamaba así, tenía por nombre Tristán ${ }^{36}$. Por su parte, el episodio de la lucha con el dragón deriva de un cuento folklórico bretón en el que el héroe mata al dragón al que va a ser sacrificada la princesa y el personaje que pretende recibir el premio de este hecho enseñando la cabeza del dragón es desenmascarado cuando el héroe trae la lengua de aquél ${ }^{37}$.

Otros posibles elementos extraídos de la cultura bretona son el tema del hombre que se casa con dos mujeres y el motivo de las velas blancas y negras.

32. NEWSTEAD (op. cit., p. 126) comenta el paralelo de este argumento con el episodio del Morlot (en ambos casos un héroe llega a un país extraño, oye las quejas del pueblo respecto a un tributo y lo libera de él) y el posterior reconocimiento de Tristán por parte de Iseo en el baño.

33. Op. cit., pp. 212-213.

34. RAYNAUD DE LAGE, Guy, "Les romans de Tristan au XIle siècle", Grundiss der Romanischen Literaturen des mittelalters, Volume IV: Le roman jusqu'à la fin du XIIe siècle, Heildelberg, Carl Winter. Universitätsverlag, 1978, Tomo I, pp. 212-230.

35 . Es el nombre de Mares en las versiones francesas.

36. NEWSTEAD, op. cit., p. 128.

37. NEWSTEAD, op. cit., p. 129. 
Si bien la abundancia de coincidencias entre la literatura y el folklore de raíces célticas y Tristán e Iseo hace imposible negar la existencia de una influencia celta en la formación de la leyenda, es preciso admitir que algunas de las "evidencias" presentadas son muy forzadas y que hay elementos que no sólo pertenecen a dicha tradición sino que forman parte del folklore universal.

La teoría del origen oriental ha sido calurosamente defendido por Pierre Gallais ${ }^{38}$. Con anterioridad ya se habían señalado algunos elementos orientales en la obra. El tema del juramento engañoso está originado en un ceremonial hindú llamado "acto de la verdad" que aparece en la mayoría de las colecciones sánscritas de cuentos. El acto de la verdad se ha transformado en la ordalía cristiana.

De procedencia árabe es el episodio del encuentro de los amantes bajo la mirada del marido, que les espía desde un árbol. Este tema aparece en fuentes árabes bien conocidas en la Francia del siglo XII. Dos fabliaux que explotan este tema son el de El árbol encantado y el de La mujer del carpintero ${ }^{39}$.

Otra fuente árabe es la historia del poeta Kais ibn Doreidsch (687) y su esposa Lobna:

Kais está forzosamente separado de su verdadero amor, su esposa Lobna, y conoce otra mujer del mismo nombre. Se casa con ella con ayuda del hermano, pero la descuida porque piensa sólo en su primer amor. Cae enfermo y envía por la primera esposa. Se reúnen, pero muere pronto.

Para Helaine Newstead, esta historia, unida a la de Diarmaid y Grainne y al tema bretón del hombre con dos esposas, podría ser el núcleo central de la formación de Tristán e Iseo ${ }^{40}$.

La teoría de Pierre Gallais parte de otra dirección. Comienza por echar por tierra los argumentos de los partidarios del origen céltico: Las semejanzas entre las novelas irlandesas y el Tristán son muy débiles. Además, los testimonios están recogidos en manuscritos posteriores a la creación de la historia de Tristán y pudieran estar influidos por ésta. Para este autor, el argumento y la elaboración de Tristán e Iseo son netamente de origen oriental. Incluso el espíritu de la historia es oriental. Gallais observa las semejanzas entre el relato europeo y una novela persa titulada Wis y Rämün escrita, entre 1050 y 1055, por Fakhn ad-Dïn As'ad Gurgäni. Las semejanzas entre ambas obras son, efectivamente, sorprendentes:

La princesa Chahrou y el rey Maubad conciertan la boda de éste con una hija de ella, aún por nacer. La niña, Wïs, es criada por una aya junto al hermano del rey Maubad, Rämïn. Cuando es mayor, Wiss vuelve con su madre que, olvidando el contrato matrimonial, decide casarla con Vïrou, que es hermano de Wïs por parte de madre. El rey Maubad reclama a Wis y estalla la guerra, en el curso de la cual muere el padre de Wis. Maubad pretende hacer la paz y casarse con la princesa, pero ella se niega diciendo que ha matado a

38. Genèse du roman occidental. Essais sur Tristan et Iseut et son modèle persan, Paris, Tête de Feuilles-Sirac, 1974.

39. En ambos cuentos el marido observa desde un árbol a su mujer con su amante. En el primero se le engaña diciéndole que lo que ha visto es efecto de un encantamiento que sufren todos los que suben a ese árbol. En el segundo los amantes descubren su presencia y fingen inocencia.

40. Op. cit., p. 132. 